OPEN ACCESS

Edited by:

Tamas Szakmany,

Cardiff University, United Kingdom

Reviewed by:

Natalija Vukovic,

University of Niš, Serbia

Eizo Watanabe,

Chiba University, Japan

Helio Penna Guimaraes,

Albert Einstein Israelite Hospital, Brazil

${ }^{*}$ Correspondence: Ming Yang

274453563@qq.com

Yingkun Guo

gykpanda@163.com

tThese authors have contributed equally to this work

‡ORCID:

Yingkun Guo

orcid.org/0000-0001-8437-9887

Specialty section:

This article was submitted to Intensive Care Medicine and Anesthesiology,

a section of the journal

Frontiers in Medicine

Received: 14 May 2020

Accepted: 27 July 2020

Published: 14 August 2020

Citation:

$X u R$, Hou K, Zhang $K, X u H$, Zhang $N$,

$F u H$, Xie L, Sun R, Wen L, Liu H,

Yang Z, Yang $M$ and Guo $Y$ (2020)

Performance of Two Risk-Stratification Models in Hospitalized Patients With

Coronavirus Disease.

Front. Med. 7:518

doi: 10.3389/fmed.2020.00518

\title{
Performance of Two
}

\section{Risk-Stratification Models in Hospitalized Patients With Coronavirus Disease}

Rong X ${ }^{1+}$, Keke Hou ${ }^{2+}$, Kun Zhang ${ }^{1+}$, Huayan $\mathrm{Xu}^{1}$, Na Zhang ${ }^{2}$, Hang $\mathrm{Fu}^{1}$, Linjun $\mathrm{Xie}^{1}$,
Ran Sun ${ }^{1}$, Lingyi Wen ${ }^{1}$, Hui Liu ${ }^{1}$, Zhigang Yang ${ }^{3}$, Ming Yang ${ }^{4 *}$ and Yingkun Guo ${ }^{1 *}$

${ }^{1}$ Key Laboratory of Birth Defects and Related Diseases of Women and Children of Ministry of Education, Department of Radiology, West China Second University Hospital, Sichuan University, Chengdu, China, ${ }^{2}$ Department of Radiology, Public Health Clinical Center of Chengdu, Chengdu, China, ${ }^{3}$ Department of Radiology, West China Hospital, Sichuan University, Chengdu, China, ${ }^{4}$ Department of Respiratory Medicine, Public Health Clinical Center of Chengdu, Chengdu, China

Background: Despite an increase in the familiarity of the medical community with the epidemiological and clinical characteristics of coronavirus disease 2019 (COVID-19), there is presently a lack of rapid and effective risk stratification indicators to predict the poor clinical outcomes of COVID-19 especially in severe patients.

Methods: In this retrospective single-center study, we included 117 cases confirmed with COVID-19. The clinical, laboratory, and imaging features were collected and analyzed during admission. The Multi-lobular infiltration, hypo-Lymphocytosis, Bacterial coinfection, Smoking history, hyper-Tension and Age (MuLBSTA) Score and Confusion, Urea, Respiratory rate, Blood pressure, Age 65 (CURB65) score were used to assess the death and intensive care unit (ICU) risks in all patients.

Results: Among of all 117 hospitalized patients, 21 (17.9\%) patients were admitted to the ICU care, and 5 (4.3\%) patients were died. The median hospital stay was 12 (10-15) days. There were 18 patients with MuLBSTA score $\geq 12$ points and were all of severe type. In severe type, ICU care and death patients, the proportion with MuLBSTA $\geq 12$ points were greater than that of CURB65 score $\geq 3$ points (severe type patients, 50 vs. $27.8 \%$; ICU care, 61.9 vs. $19.0 \%$; death, 100 vs. $40 \%$ ). For the MuLBSTA score, the ROC curve showed good efficiency of diagnosis death (area under the curve [AUC], 0.956; cutoff value, 12; specificity, 89.5\%; sensitivity, 100\%) and ICU care (AUC, 0.875; cutoff value, 11; specificity, 91.7\%; sensitivity, 71.4\%). The K-M survival analysis showed that patients with MuLBSTA score $\geq 12$ had higher risk of ICU (log-rank, $P=0.001)$ and high risk of death (log-rank, $P=0.000$ ).

Conclusions: The MuLBSTA score is valuable for risk stratification and could effectively screen high-risk patients at admission. The higher score at admission have higher risk of ICU care and death in patients infected with COVID.

Keywords: risk-stratification, coronavirus disease, MuLBSTA score, CURB65 score, ICU 


\section{INTRODUCTION}

In December 2019, a series of pneumonia cases of unknown cause emerged in Wuhan, Hubei Province, China. Subsequently, a novel coronavirus was isolated and is known as the 2019 novel coronavirus (SARS-COV-2), which was designated as coronavirus disease 2019 (COVID-19) (1). With the worldwide prevalence and outbreak of COVID-19, the pressure regarding the prevention and treatment of this epidemic has intensified, and several local medical resources were seriously insufficient (2). Thus, understanding the risk stratification could help in the better allocation of the available medical resources as well as ensure appropriate clinical management of high-risk patients to improve the survival rate.

The clinical spectrum of COVID-19 infection appears to be wide, encompassing asymptomatic infection, mild upper respiratory tract illness, severe viral pneumonia with respiratory failure, shock, and even death. The current reported death rate is about $0.66-7.2 \%(1,3-5)$. Some studies have published the risk factors that may be associated with poor prognosis, such as age or severe immune response (4-7). However, only a few studies focusing on clinical risk stratification, and the risk factors for in-hospital death or intensive care unit (ICU) care of patients were undefined.

An effective and comprehensive model for screening high-risk patients at admission is necessary for patients infected with SARS-COV-2. Therefore, we aimed to verify the efficacy of the Multi-lobular infiltration, hypo-Lymphocytosis, Bacterial coinfection, Smoking history, hyper-Tension, and Age (MuLBSTA) scale for mortality or ICU risk stratification in patients with COVID-19 and clarify the predictive value of the scale for poor prognosis.

\section{METHODS}

\section{Study Design and Data Collection}

We recruited patients from January 1 to March 25, 2020 in this retrospective study. All patients were diagnosed with COVID-19 pneumonia according to RT-PCR. All laboratory and imaging reports during the hospitalization were recorded. The institutional ethic committee of our institutes approved this study (No. 2020.43).

History of exposure, clinical manifestations, laboratory findings, CT characteristics, and epidemiological and outcome data were obtained from the collection forms and electronic medical records from admission to discharge. All recorded data were independently reviewed by two researchers.

\section{CT Image Review}

Signs and severity of lung lesions observed in Computed Tomography (CT) scans were evaluated, and lung involvement in each lobe was recorded. More than three lung lobes involvement were regarded as multi-lobular infiltrates. The "total severity score" was calculated by summing the five lobe scores (range: $0-$ 25 points), and each of the five lung lobes were visually scored from 0 to 5 (8). All CT images were independently reviewed by two fellowship-trained cardiothoracic radiologists, and final decisions were reached by consensus.

\section{MuLBSTA Score and CURB 65 Score}

The MuLBSTA Score were scaled in all patients. The score points as follows: Multi-lobular infiltrates (5 points), lymphocyte count $\leq 0.8 \times 10^{9} / \mathrm{L}$ ( 4 points), bacterial coinfection ( 4 points, presented with bacteria positive by laboratory tests or sputum tests and there were consolidation signs on CT feature), acute smoker ( 3 points, and the patients who had quit-smoking history were scaled as 2 points), hypertension ( 2 points), and age $\geq 60$ years ( 2 points). All patients received a total score calculation for MuLBSTA score. A score of 12 points was used as the cutoff value for mortality risk stratification [MuLBSTA 0-11 (low-risk" mortality) and MuLBSTA 12-22 (high-risk mortality)] (9).

Confusion, Urea, Respiratory rate, Blood pressure, Age 65 (CURB65) score were also scaled. The CURB65 is recommended for assessing the severity of pneumonia in hospital settings and the score system refer to previous studies $(10,11)$.

\section{Clinical Outcomes}

Complications such as electrolyte disturbance, acute myocardial injury (AMI), acute kidney injury (AKI), acute respiratory distress syndrome (ARDS), and shock were recorded. The time from onset to admission and from admission to discharge were also recorded. Clinical outcomes included Death, ICU care, and recovery/discharge.

TABLE 1 | Baseline, clinical treatment, and outcome of all patients.

\begin{tabular}{lclc}
\hline Baseline & $\begin{array}{c}\text { Total } \\
(\mathbf{N = 1 1 7 )}\end{array}$ & Treatment & $\begin{array}{c}\text { Total } \\
(\mathbf{N = 1 1 7 )}\end{array}$ \\
\hline Age (years) & & Severity type & \\
$<40$ & $37(31.6 \%)$ & Common type & $81(69.2 \%)$ \\
$40-59$ & $45(38.5 \%)$ & Severe type & $16(13.7 \%)$ \\
$\geq 60$ & $35(29.9 \%)$ & Critically severe type & $20(17.1 \%)$ \\
Male & $55(47.0 \%)$ & Support Treatment & \\
Hypertension & $19(16.2 \%)$ & High flow oxygen & $19(16.2 \%)$ \\
Diabetes & $18(15.4 \%)$ & Non-invasive & $7(6.0 \%)$ \\
& & Invasive & $6(5.1 \%)$ \\
CVD & $8(6.8 \%)$ & CRRT & $9(7.7 \%)$ \\
CKD & $5(4.3 \%)$ & ECMO & $1(0.8 \%)$ \\
Obesity & $16(13.8 \%)$ & & \\
Clinical outcome & & & \\
ICU care & $21(17.9 \%)$ & Medicine treatment & \\
Discharged & $96(82.1 \%)$ & Antiviral & $105(89.7 \%)$ \\
Death & $5(4.3 \%)$ & Antibiotic & $26(22.2 \%)$ \\
Interval time & & Thymalfasin & $13(11.1 \%)$ \\
Onset to admission (days) & $5(3-7)$ & Chinese medicinal & $81(69.2 \%)$ \\
Onset to discharge (days) & $16(14-23)$ & Interferon & $104(88.9 \%)$ \\
Admission to discharge & $12(10-15)$ & Convalescent plasma & $8(6.8 \%)$ \\
(days) & & & \\
\hline & & & \\
\hline
\end{tabular}

Date are $n$ (\%), mean $\pm S D$, or median (IQR). CVD, cardiovascular disease; ICU, intensive care unit; CRRT, continuous renal replacement therapy; ECMO, extracorporeal membrane oxygenation. 
TABLE 2 | The clinical characteristics and CT feature in different type patients.

\begin{tabular}{|c|c|c|c|}
\hline & $\begin{array}{c}\text { Total } \\
N=117\end{array}$ & $\begin{array}{l}\text { Common type } \\
\qquad N=81\end{array}$ & $\begin{array}{l}\text { Severe type } \\
\qquad N=36\end{array}$ \\
\hline BMI & $23.5 \pm 3.8$ & $23.4 \pm 3.9$ & $23.7 \pm 3.9$ \\
\hline CURB65 score & $0.6 \pm 1.0$ & $0.2 \pm 0.5$ & $1.4 \pm 1.2^{\star}$ \\
\hline Prone positioning & $12(33.3 \%)$ & $0(0 \%)$ & 12 (33.3\%) \\
\hline \multicolumn{4}{|l|}{ Laboratory } \\
\hline Lymphocyte $\left(10^{9 / /}\right)$ & $1.4 \pm 1.2$ & $1.7 \pm 1.3$ & $0.9 \pm 0.4^{*}$ \\
\hline Decreased & $34(29.1 \%)$ & $13(16.0 \%)$ & $21(58.3 \%)$ \\
\hline Lymphocyte rate (\%) & $22.9 \pm 11.3$ & $27.8 \pm 9.9$ & $15.5 \pm 7.9^{*}$ \\
\hline Decreased & 45 (38.5\%) & $17(19.1 \%)$ & $28(77.8 \%)^{*}$ \\
\hline CRP (mg/L) & $20.1 \pm 30.9$ & $10.5 \pm 21.3$ & $38.7 \pm 36.4^{*}$ \\
\hline Increased & $67(57.3 \%)$ & 34 (42.0\%) & $33(91.7 \%)^{*}$ \\
\hline \multicolumn{4}{|l|}{ CT imaging } \\
\hline $\begin{array}{l}\text { Interval time from } \\
\text { symptoms onset to CT } \\
\text { (days) }\end{array}$ & $11(6-18)$ & $10(6-17)$ & $13(9-20)$ \\
\hline$\geq 3$ Lung lobes affected & $82(70.1 \%)$ & 48 (59.3\%) & $34(94.4 \%)^{*}$ \\
\hline$>2$ Mixture signs & 88 (75.2\%) & 53 (59.6\%) & $35(97.2 \%)^{\star}$ \\
\hline Total lung severity & $4.7 \pm 3.6$ & $3.3 \pm 2.4$ & $7.8 \pm 3.9^{\star}$ \\
\hline
\end{tabular}

${ }^{*} P<0.05$ vs. common type. Date are $n(\%)$, mean $\pm S D$, or median (IQR). CT, computerized tomography; BMI, body mass index; CURB65, confusion, urea, respiratory rate, blood pressure, age 65; CRP, Creative protein.

TABLE 3 | The MULBSTA score and complications in different type patients.

\begin{tabular}{|c|c|c|c|}
\hline & $\begin{array}{c}\text { Total } \\
N=117\end{array}$ & $\begin{array}{l}\text { Common type } \\
\qquad N=81\end{array}$ & $\begin{array}{c}\text { Severe type } \\
\qquad N=36\end{array}$ \\
\hline MuLBSTA score & $8 \pm 5$ & $6 \pm 4$ & $11 \pm 5^{\star}$ \\
\hline$\geq 12$ & 18 (15.4\%) & $0(0)$ & $18(50.0 \%)^{\star}$ \\
\hline Age $\geq 60$ years & 35 (29.9\%) & 15 (18.5\%) & $20(55.6 \%)^{\star}$ \\
\hline Hypertension & 19 (16.2\%) & $5(6.2 \%)$ & $14(38.9 \%)^{\star}$ \\
\hline Smoker & 11 (9.4\%) & $4(4.9 \%)$ & 7 (19.4\%) \\
\hline $\begin{array}{l}\text { Lymphocyte } \\
<0.8^{\star} 10^{9} / L\end{array}$ & $33(28.2 \%)$ & 13 (16.0\%) & 20 (55.6\%) \\
\hline $\begin{array}{l}\text { Multi-lobular } \\
\text { infiltrates }\end{array}$ & 66 (56.4\%) & 36 (44.4\%) & 30 (83.3\%) \\
\hline $\begin{array}{l}\text { Bacterial } \\
\text { coinfection }\end{array}$ & 28 (23.9\%) & 9 (11.1\%) & $19(52.8 \%)^{*}$ \\
\hline \multicolumn{4}{|l|}{ Complications } \\
\hline $\begin{array}{l}\text { Electrolyte } \\
\text { disturbance }\end{array}$ & 31 (26.5\%) & 12 (14.8\%) & $19(52.8 \%)^{\star}$ \\
\hline AMI & 12 (10.3\%) & 2 (2.5\%) & $11(30.6 \%)^{*}$ \\
\hline Respiratory failure & 17 (14.5\%) & $0(0 \%)$ & $17(47.2 \%)^{*}$ \\
\hline AKI & $3(2.6 \%)$ & $1(1.2 \%)$ & 2 (5.5\%) \\
\hline ARDS & $5(4.3 \%)$ & $0(0 \%)$ & 5 (13.9\%) \\
\hline Shock & 4 (3.4\%) & $0(0 \%)$ & $4(11.1 \%)$ \\
\hline
\end{tabular}

${ }^{*} P<0.05$ vs. common type. AMI, acute myocardial injury; AKI, acute kidney injury; ARDS, acute respiratory distress syndrome.

\section{Statistical Analysis}

All tests were two-sided, and $P<0.05$ was considered statistically significant. Categorical variables were described as frequency rates or percentages, and continuous variables were presented as mean (SD) or median (IQR). The mean values for continuous variables were compared using the independent $t$-tests when the data were normally distributed; otherwise, the Mann-Whitney test was used. For laboratory results, we also assessed whether the measurements were outside the normal range. The ROC curve was used to examine the efficacy of the MuLBSTA score for death or ICU. The Kaplan-Meier (K-M) survival analysis was performed to estimate the survival probabilities for COVID19 infection by the log-rank test. All statistical analyses were performed using 22.2 SPSS software (Statistical Package for the Social Sciences).

\section{RESULTS}

\section{Presenting Characteristics}

The study population included 117 hospitalized patients with confirmed cases of COVID-19. The youngest patient was 3 months old. Furthermore, 2 patients were admitted with mild symptoms and classified as common type, but then were classified as critically severe type after admission due to the symptoms rapidly aggravated. Moreover, there were $35(29.9 \%)$ patients were older than 60 years. A total of $55(47.0 \%)$ patients were men. The underlying diseases showed in Table 1. For the clinical severity type, $81(69.2 \%)$ patients were common type, and 16 (13.7\%) and $20(17.1 \%)$ were severe and critically severe types, respectively. Among all patients, most of them $(96,82.1 \%)$ were discharged, $21(17.9 \%)$ were admitted to the ICU, and $5(4.3 \%)$ died.

Of all 117 patients, the symptomatic treatment and invasive treatment were shown in Table 1. Among of nine patients with continuous renal replacement therapy, three were acute kidney injury, six were electrolyte disturbance or hypercytokinemia (2 patients had concurrent both of two conditions). And five patients were chronic kidney injury. One received extracorporeal membrane oxygenation due to the condition continues to deteriorate. Otherwise, the medicine treatment were also showed in Table 1, there were $8(6.8 \%)$ patients repeatedly tested PCR positive, stayed in the hospital for more than 30 days, and received convalescent plasma (from cared patients).

\section{The Clinical Characteristics and CT Feature in Different Patients}

In all patients, there was no statistical difference in body mass index (BMI) between common type and severe type patients. Among all severe type patients, the mean point of CURB65 score was $1.4 \pm 1.5$. And $12(33.3 \%)$ of the patients underwent the prone position management.

The lymphocyte count and rate in severe type patient were significantly lower than those in common type patients $(P$ $<0.05)$. Among the severe type patients, $21(58.3 \%)$ and 28 (7.8\%) presented with decreased lymphocyte count and rate, respectively, of which the percentages were higher than those in common type patients. Furthermore, the increased CPR level was higher in severe type patients than in common type patients (33 [91.7\%] vs. $34[42.0 \%])$. 
For the assessment of CT features, in all of 36 severe type patients, $34(94.4 \%)$ and $35(97.2 \%)$ showed more than 3 lung lobes affected and more than 2 mixture signs, respectively. The lung lobes involvement was shown in Table 2. Severe type patients had significantly higher lung severity scores than common type patients $(7.8 \pm 3.9$ vs. $3.3 \pm 2.4, P<0.05)$.

\section{The Scores and Clinical Complications}

A total of 18 patients had a MuLBSTA score $>12$ points and were all of severe type (Table 3 ). In the severe type patients, 20 (55.6\%) were older than 60 years, 14 (38.9\%) had hypertension, 7 (19.4\%) were smokers, $20(55.6 \%)$ had a lymphocyte count of $<0.8 * 10^{9} / \mathrm{L}, 30(83.3 \%)$ had multi-lobular infiltrates, and 19 (52.8\%) had bacterial coinfection. The frequency of all the terms in severe type patients was higher than that in the common type patients.

For CURB65 score, the mean point in severe type patients were significantly higher than common type patients $(P<0.05)$. Among of 36 severe type patients, there were 16 patients and 10 patients were more than 2 points and 3 points, respectively. In ICU care and death patients, there were $4(19.0 \%)$ patients and 2 (40\%) patients had CURB65 score more than 3 points. The proportion of MuLBSTA score more than 12 points was much higher compared with the proportion of CURB65 score more than 3 points in ICU care and deaths $(P<0.05)$ (Figure 1$)$.

During admission, the complications of severe type patients were as follows: 19 (52.8\%) patients had with electrolyte disturbance; 11 (30.6\%) with AMI; 17 (47.2\%) with respiratory failure; 2 (5.5\%) with AKI; and 5 (13.9\%) with ARDS. Moreover, $4(11.1 \%)$ patients experienced shock and were all of severe type.
The frequency of electrolyte disturbance, AMI and respiratory failure in severe type patients were higher than common type patients. The hypokalemia and respiratory failure type I were most common (Table 3).

\section{Efficacy and Prognosis Value of the MuLBSTA Scale for Death or ICU Care}

Of all 21 patients who required ICU care, 13 (61.9\%) and 16 $(71.9 \%)$ had a MuLBSTA score $>12$ points. The median point of the MuLBSTA score was 13 (IQR, 9, 15). All (100\%) patients who died had a MuLBSTA score $\geq 12$ points, and the median point was 17 (IQR, 14, 17).

The diagnosis of the MuLBSTA score for death or ICU treatment is shown in Figure 2. The area under the curve (AUC) of death diagnosis was 0.956 , the cutoff value was 12 (specificity, 89.5\%; sensitivity, $100 \%$ ). The AUC of ICU diagnosis was 0.875 , and the cutoff value was 11 (specificity, 91.7\%; sensitivity, 71.4\%).

The subgroup analysis of the association between the MuLBSTA score and death or ICU care patients were showed in Figure 3. Patients with a MuLBSTA score $\geq 12$ had a higher ICU care (log-rank, $P=0.001)$ and higher death (log-rank, $P=$ 0.000 ) risks. The decreasing number of patients at high risk group and the total number of deaths accumulated over time and ICU admissions in the cohort are shown in Figure 3.

\section{DISCUSSION}

In this cohort study, we reported the clinical characteristics and available risk stratification scores associated with the clinical outcomes in patients with COVID-19 pneumonia who died or

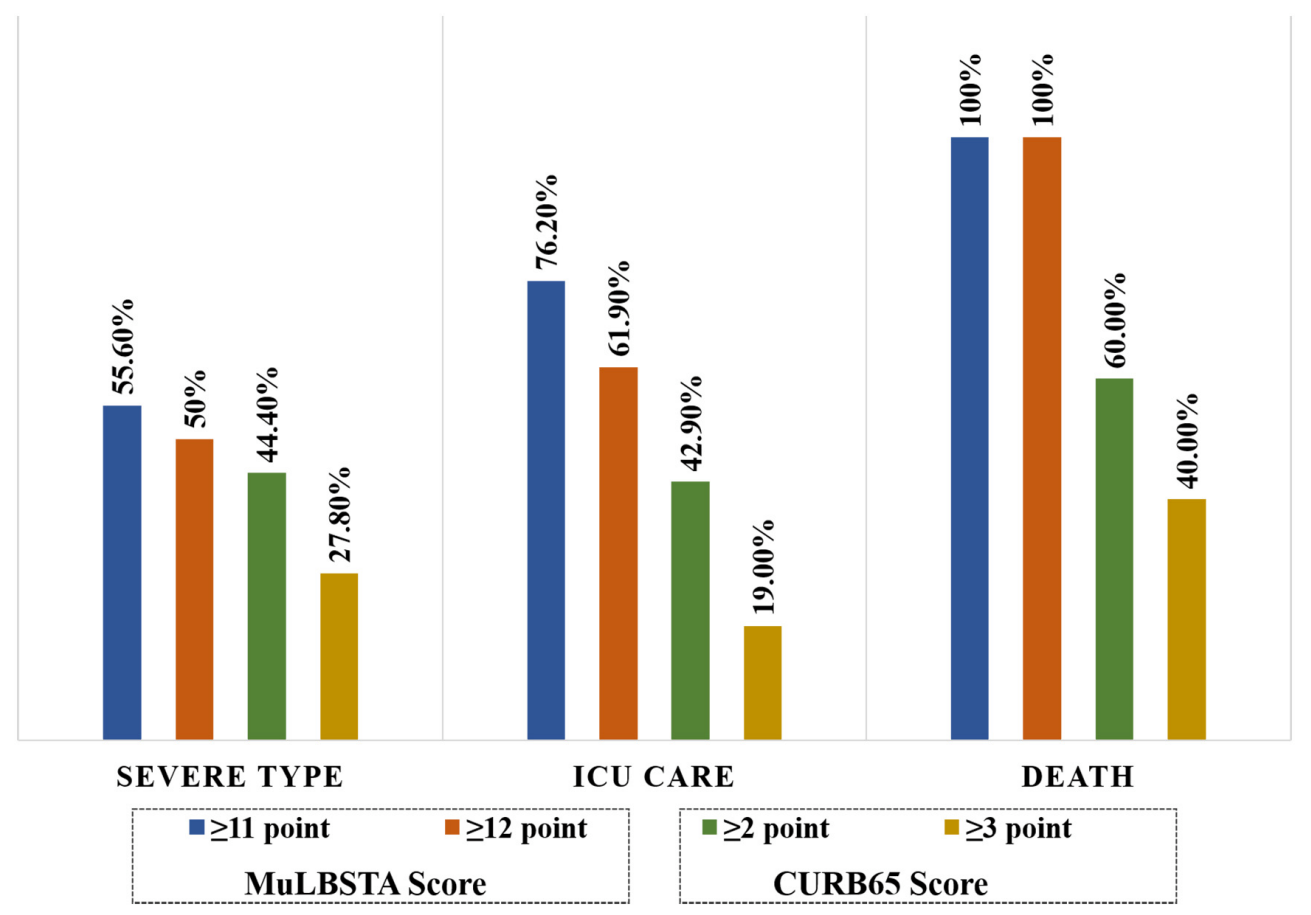

FIGURE 1 | The proportion of different MuLBSTA and CURB65 score points in severe type patients. 

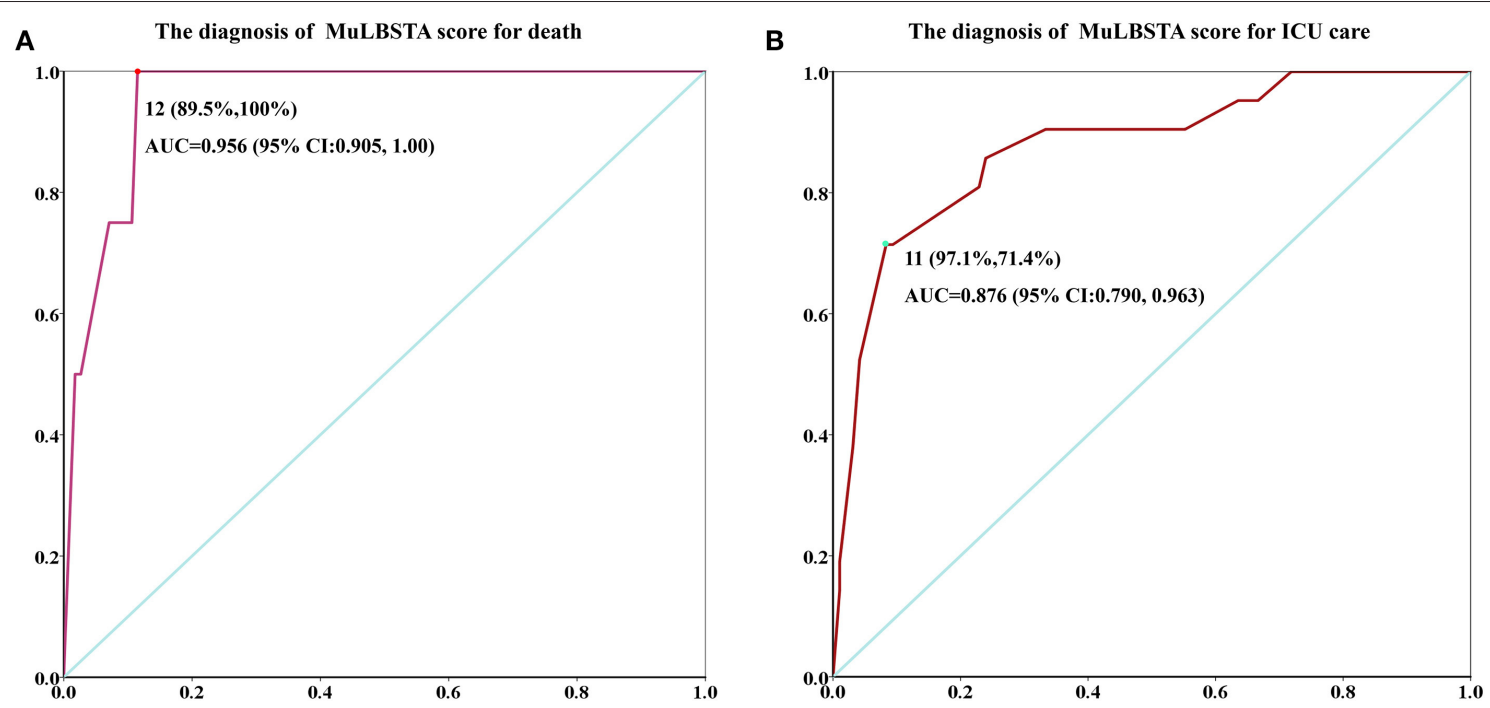

FIGURE 2 | ROC curve of the MuLBSTA score. (A) The AUC of death. (B) The AUC of ICU.
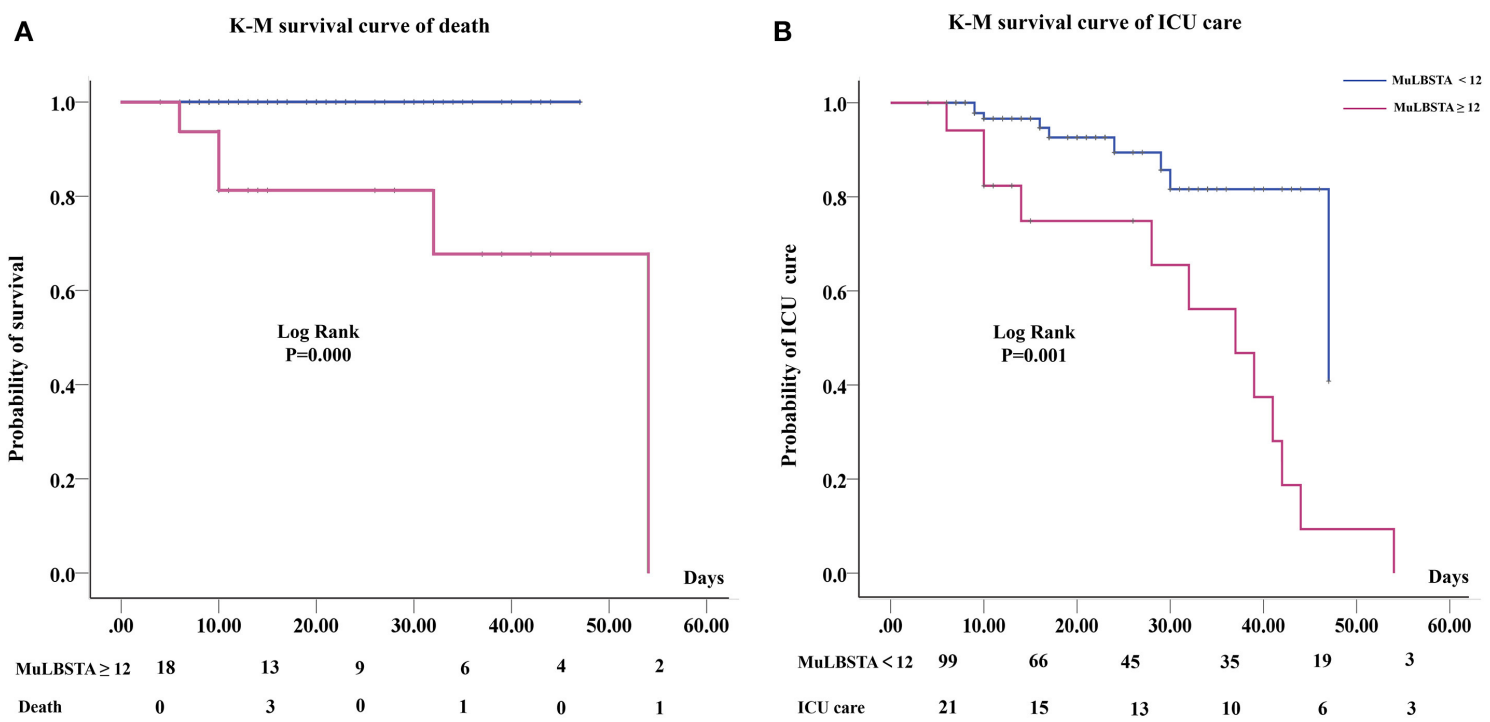

FIGURE 3 | K-M curve of different MuLBSTA scores patients and count of patients in each group at risk at each interval. (A) Death risk of MuLBSTA score of $\geq 12$; (B) The ICU care needs of MuLBSTA score of $\geq 12$.

required ICU care after admission. Patients with a MuLBSTA score $\geq 12$ points were more likely to die or require ICU care. Particularly, severe type patients were more likely to be older, associated with more underlying diseases, severe immune response and lung involvement. These findings suggest that for patients with COVID-19, the MuLBSTA score at first-time hospital admissions may be necessary for risk stratification in patients who have poor prognosis.

As a new type of highly contagious disease in human, this is the first coronavirus to cause a human pandemic (12). The pathophysiology and risk factors of unusually high mortality for COVID-19 have not yet been completely understood. In this study, we validated an effective clinical risk stratification scoring scale-MuLBSTA score for patients infected with SARSCOV-2. This scale is based on the mortality outcomes of 528 patients infected with respiratory viruses according to Guo et al. (9). However, there is no sufficient evidence to verify the efficacy of assessment of poor prognosis in COVID-19 patients (13). The scale is used as an early warning model in predicting mortality in viral pneumonia (9). This scale synthesizes multiple risk factors of the patient, and finally obtains a total score according to the proportions of different risk factor, which is equivalent to the score of the patient's basic condition. 
Old age and underlying diseases are now well-known as risk factors in COVID-19 patients, and it has been reported that the SARS-COV-2 infection was more like to occur in older men with comorbidities (13-15). Wu et al. thought that older age was associated with a greater risk of developing ARDS and death, and it may be owing to less rigorous immune response (16). In their cohort, $29.9 \%$ of patients were older than 60 years, and 16.2 and $15.4 \%$ had associated with hypertension and diabetes. Hypertension and CVD had higher prevalence in the severe cases than in the mild ones. Moreover, no study have demonstrated that a single underlying illness is a risk factor for death or treatment in the ICU at present. Old age or age and underlying disease alone may not be sufficient to determine the risk. In earlier reports increased age in the male population has been associated with higher mortality (17). Smokers are vulnerable to respiratory viruses, and smoking could upregulate angiotensinconverting enzyme 2 receptor levels (17). The prevalence of high smoking level in males may partly explain the higher susceptibility and mortality of male patients.

In addition, virus-induced direct cytopathic effects and viral evasion of host immune responses are believed to play major roles in the severity of coronavirus infection $(18,19)$. The dysregulation of immune response may result in an excessive inflammation, leading to adverse outcomes $(20,21)$. Lymphocytopenia was present in $83.2 \%$ patients with COVID19 at admission (22), and severe cases tend to have lower lymphocyte counts (5). In this study, we had similar findings that lymphocyte counts significantly decreased in severe type patients, and more than half of patients had decreased lymphocyte count. Coronaviruses commonly attack the respiratory system and SARS-CoV-2 has been shown to cause lung damage $(22,23)$. As a significant auxiliary modality, chest CT is a key component of the diagnosis of virus-infected patients (24). It allows the sensitive assessment of lung lesions as well as the degree and location of lung involvement. In previous studies, ground glass and consolidation opacities have been shown to be the most common imaging signs in patients with COVID-19 $(8,23,25)$. Although weakened immunity and lung damage are problems in the majority of patients, the effect on death or ICU remains unclear.

The MuLBSTA score is a good diagnostic marker for poor prognosis. In the present study, a score of 12 points indicates the specificity and sensitivity of death were 89.5 and $100 \%$, and 11 points present the specificity and sensitivity of ICU care were 91.7 and $71.4 \%$, respectively. These results strongly suggest that the scale has good efficacy to assess the clinical risk of death and ICU care in patients infected with SARS-COV-2. The survival analysis showed that the higher is the MuLBSTA score, the higher is the death risk. In our results, $50 \%$ of severe type patients had a score of $\geq 12$ points, but no common type patients had more than this score. The results implied that severe type patients are more likely to die, and it may be owing to severe immune response and lung involvement.

In clinical practices, there is no effective treatment available for the infected patients, but screening high-risk patients at first admission and appropriate clinical management may be helpful in reducing the incidence of severe complications, such as ARDS or sepsis as well as mortality. Although there are some clinical scales about the severity and risk stratification of pneumonia, such as CURB65 or SOFA score, but in our study, the screening proportion of high-risk patients with MuLBSTA score was higher than that of CURB65 score. Meanwhile, age, hypertension, and smoking status as part of the MuLBSTA score were readily available in the clinical setting, whereas the lymphocyte count and lobe status were assessed by routine blood examination and $\mathrm{X}$-ray or CT scan. Therefore, the score may be a rapid and effective risk stratification strategy.

This study has several limitations. First, the lack of effective antiviral drugs, and all patients underwent different treatment regimens, which may affect the prognosis of patients. Secondly, there may be other risk factors that also affect the prognosis of patients. We verified the validity of the MuLBSTA scale, but the predictive value of a single factor was not analyzed. Finally, because this is the retrospective study, we could only evaluate the short-term prognosis. The long-term prognosis would be analyzed in further studies.

To the best of our knowledge, this is the first retrospective cohort study that focusing on the MuLBSTA score risk stratification of patients with COVID-19 who have experienced a definite outcome. We found that a MuLBSTA score of $\geq 12$ points at admission was a high risk factor for death or ICU care in adult patients with COVID-19. The risk stratification provides the evidence for novel coronavirus clinical interventions in efforts to improve outcomes.

\section{CONCLUSIONS}

A higher MuLBSTA score at admission had higher death or ICU risk in patients with COVID-19. The MuLBSTA scale is valuable for the risk stratification of COVID-19 patients, especially regarding death or ICU care.

\section{DATA AVAILABILITY STATEMENT}

All datasets generated for this study are included in the article/supplementary material.

\section{ETHICS STATEMENT}

The study was approved by the hospital ethics committee. Written informed consent was waived owing to the rapid emergence of this infectious disease.

\section{AUTHOR CONTRIBUTIONS}

MY and YG designed the study and takes responsibility for the integrity and accuracy of the data analysis. $\mathrm{RX}, \mathrm{KH}$, and $\mathrm{KZ}$ contributions to the acquisition, analysis, interpretation of data for the work, and writing of the manuscript. RX, KH, KZ, HX, $\mathrm{NZ}, \mathrm{HF}, \mathrm{LX}, \mathrm{RS}, \mathrm{LW}, \mathrm{HL}$, and ZY had roles in patient recruitment, data collection, and clinical management. All authors contributed to data acquisition, data analysis, and all reviewed and approved the final version of the manuscript. 


\section{FUNDING}

This work was supported by 2020 Novel coronavirus pneumonia prevention and control technology project of Chengdu (No. 2020-YF05- 00007-SN); Clinical research finding of Chinese society of cardiovascular disease (CSC) of 2019 (HFCSC2019B01); the National Natural Science Foundation of China (Nos. 81771887, 81771897, 81971586, and 81901712); the Program for Young Scholars and Innovative Research Team in Sichuan Province (No. 2017TD0005) of China; and $1 \cdot 3 \cdot 5$ project

\section{REFERENCES}

1. Wu ZY, McGooga JM. Characteristics of and important lessons from the Coronavirus Disease 2019 (COVID-19) outbreak in China summary of a report of 72314 cases from the Chinese center for disease control and prevention. JAMA. (2020) 323:1239-42. doi: 10.1001/jama.2020.2648

2. WHO. WHO Director-General's Opening Remarks at the Media Briefing on COVID-19 - 3 April 2020. (2020). Available online at: https://www. who.int/dg/speeches/detail/who-director-general-s-opening-remarksat-the-media-briefing-on-covid-19--3-april-2020 (accessed April 3, 2020).

3. Cao Y, Liu X, Xiong L, Cai K. Imaging and clinical features of patients with 2019 novel coronavirus SARS-CoV-2: a systematic review and meta-analysis. J Med Virol. (2020). doi: 10.1002/jmv.25822. [Epub ahead of print].

4. Mahase E. COVID-19: death rate is $0.66 \%$ and increases with age, study estimates. BMJ. (2020) 369:m1327. doi: 10.1136/bmj. m1327

5. Qin CN, Zhou LQ, Hu ZW, Shoqi Z, Sheng Y, Yu T, et al. Dysregulation of immune response in patients with COVID-19 in Wuhan, China. Clin Infect Dis. (2020) 71:762-8. doi: 10.2139/ssrn.3541136

6. Graziano O, Giovanni R, Silvio B. Case-fatality rate and characteristics of patients dying in relation to COVID-19 in Italy. JAMA. (2020) 323:1775-6. doi: 10.1001/jama.2020.4683

7. Liu J, Zheng X, Tong Q, Li W, Wang B, Sutter K, et al. Overlapping and discrete aspects of the pathology and pathogenesis of the emerging human pathogenic coronaviruses SARS-CoV, MERS-CoV, and 2019-nCoV. J Med Virol. (2020) 92:491-4. doi: 10.1002/jmv.25709

8. Michael C, Adam B, Xueyan M, Ning Z, Mingqian H, Zeng X, et al. CT Imaging features of 2019 Novel Coronavirus (2019-nCoV). Radiology. (2020) 295:202-7. doi: 10.1148/radiol.2020200230

9. Guo L, Wei D, Zhang X, Wu Y, Li Q, Zhou M, et al. Clinical features predicting mortality risk in patients with viral pneumonia: the MuLBSTA score. Front Microbiol. (2019) 10:2752. doi: 10.3389/fmicb.2019.02752

10. Lim WS, van der Eerden MM, Laing R, Boersma WG, Karalus N, Town GI, et al. Defining community acquired pneumonia severity on presentation to hospital: an international derivation and validation study. Thorax. (2003) 58:377-82. doi: 10.1136/thorax.58.5.377

11. Lim WS, Baudouin SV, George RC, Hill AT, Le Jeune I, Macfarlane JT, et al. BTS guidelines for the management of community acquired pneumonia in adults: update. Thorax. (2009) 64(Suppl 3):iii1-55. doi: 10.1136/thx.2009.121434

12. WHO. Available online at: https://www.who.int/dg/speeches/detail/whodirector-general-s-opening-remarks-at-the-mission-briefing-on-covid-19\$-\$2-april-2020 (2020). (accessed April 2, 2020).

13. Chen N, Zhou M, Dong X, Qu J, Gong F, Han Y, et al. Epidemiological and clinical characteristics of 99 cases of 2019 novel coronavirus pneumonia in Wuhan, China: a descriptive study. Lancet. (2020) 395:507-13. doi: 10.1016/S0140-6736(20)30211-7

14. Huang C, Wang Y, Li X, Ren L, Zhao J, Hu Y, et al. Clinical features of patients infected with 2019 novel coronavirus in Wuhan, China. Lancet. (2020) 395:497-506. doi: 10.1016/S0140-6736(20)30183-5 for disciplines of excellence, West China Hospital, Sichuan University (No. ZYGD18013).

\section{ACKNOWLEDGMENTS}

We thank all our colleagues who helped us during the current study. We are also grateful to the many front-line medical staff for their dedication in the face of this outbreak, despite the potential threat to their own lives and the lives of their families.

15. Li JY, You Z, Wang Q, Zhou ZJ, Qui Y, Luo R, et al. The epidemic of 2019-novel-coronavirus (2019-nCoV) pneumonia and insights for emerging infectious diseases in the future. Microbes Infect. (2020) 22:80-5. doi: 10.1016/j.micinf.2020.02.002

16. Wu CM, Chen XY, Cai YP, Xia J, Xu S, Huang H, et al. Risk factors associated with acute respiratory distress syndrome and death in patients with coronavirus disease 2019 pneumonia in Wuhan, China. JAMA Intern Med. (2020) 2020:e200994. doi: 10.1001/jamainternmed.2020.0994

17. Brake SJ, Barnsley K, Lu W, McAlinden KD, Eapen MS, Sohal SS, et al. Smoking upregulates angiotensin-converting enzyme-2 receptor: a potential adhesion site for novel coronavirus SARS-CoV-2 (COVID-19). J Clin Med. (2020) 9:E841. doi: 10.3390/jcm9030841

18. Min CK, Cheon S, Ha NY, Sohn KM, Kim Y, Aigerim A, et al. Comparative and kinetic analysis of viral shedding and immunological responses in MERS patients representing a broad spectrum of disease severity. Sci Rep. 6:25359. doi: 10.1038/srep25359

19. Channappanavar R, Perlman S. Pathogenic human coronavirus infections: causes and consequences of cytokine storm and immunopathology. Semin Immunopathol. (2017) 39:529-39. doi: 10.1007/s00281-017-0629-x

20. Shaw AC, Goldstein DR, Montgomery RR. Age-dependent dysregulation of innate immunity. Nat Rev Immunol. (2013) 13:875-87. doi: 10.1038/nri 3547

21. Guan WJ, Ni ZY, Hu Y, Liang W, Ou C, He J, et al. Clinical characteristics of coronavirus disease 2019 in China. N Engl J Med. (2020) 382:1708-20. doi: 10.1056/NEJMoa2002032

22. Hyun JK, Soyeoun L, Jooae C, Choi SH, Sung H, Do KH, et al. Radiographic and CT features of viral pneumonia. RadioGraphics. (2018) 38:719-39. doi: $10.1148 / \mathrm{rg} .2018170048$

23. Ai T, Yang ZL, Hou HY, Zhan C, Chen C, Lv W, et al. Correlation of Chest CT and RT-PCR testing in coronavirus disease 2019 (COVID19) in China: A Report of 1014 Cases. Radiology. (2020) 296:E32-40. doi: 10.1148/radiol.2020200642

24. Zu ZY, Jiang MD, Xu PP, Chen W, Ni Q, Lu GM, et al. Coronavirus disease 2019 (COVID-19): a perspective from China. Radiology. (2020) 296:200490. doi: 10.1148/radiol.2020200490

25. Shi HS, Han XY, Jiang NC, Cao Y, Alwalid O, Gu J, et al. Radiological findings from 81 patients with COVID-19 pneumonia in Wuhan, China: a descriptive Study. Lancet Infect Dis. (2020) 20:425-34. doi: 10.1016/S1473-3099(20)30086-4

Conflict of Interest: The authors declare that the research was conducted in the absence of any commercial or financial relationships that could be construed as a potential conflict of interest.

Copyright (c) $2020 \mathrm{Xu}$, Hou, Zhang, Xu, Zhang, Fu, Xie, Sun, Wen, Liu, Yang, Yang and Guo. This is an open-access article distributed under the terms of the Creative Commons Attribution License (CC BY). The use, distribution or reproduction in other forums is permitted, provided the original author(s) and the copyright owner(s) are credited and that the original publication in this journal is cited, in accordance with accepted academic practice. No use, distribution or reproduction is permitted which does not comply with these terms. 